\title{
Fatigue Resistance of 01420 S Alloy Welded Joints Made by Various Welding Methods
}

\author{
Victor Ovchinnikov ${ }^{1}$, Lyudmila Andreeva ${ }^{1,}{ }^{*}$, Gulnara Latypova $^{1}$, and Irina Klimenko ${ }^{1}$ \\ ${ }^{1}$ Moscow Polytechnic University, Moscow, Russia
}

\begin{abstract}
Fatigue characteristics of welded joints of alloy $01420 \mathrm{C}$ made by resistance spot welding and automatic argon arc welding are obtained. The highest durability was shown by welded joints with a longitudinal weld. Joints Produced by resistance welding and simulating the edge line of a reinforced element have a durability comparable to an unloaded weld spot, which in turn is inferior to the durability of a joint with a longitudinal weld. The durability of elements of limited cross-section with repair welding of a mechanical cut is similar to the durability of a standard sample in the form of a strip with a hole.
\end{abstract}

\section{Introduction}

The development of state-of-the-art airframe structures is determined by solving the problems of increasing the load ratio and increasing its service life. To solve these problems, it is necessary to develop new materials and technologies for manufacturing parts and welded assemblies in general. One of the ways to solve the problem of increasing the load ratio of the airframe is applying aluminum alloys with reduced density in its structure and welding as a method of joining parts.

One of the main characteristics that determine the possibility of using the alloy is the fatigue resistance of its welded joints, which in turn depends on factors of a metallurgical nature, the geometry of the welded joints, as well as on the damage extent to the weld metal by defects $[1,2]$.

The purpose of this work was to study the fatigue resistance characteristics of $01420 \mathrm{~S}$ alloy on the main structural and technological types of welded joints of sheet semi-finished products.

\section{Materials and research methods}

The object of the study was welded samples manufactured from of 0420S alloy sheets with a thickness of $2.5 \mathrm{~mm}$. The investigated samples were prepared as follows:

- a sample with cover plate, welded by resistance spot welding (RSW) (Fig. 1, a);

- a sample with cover plate, welded by resistance spot welding (RSW), simulating the edge line of a reinforced element (Fig. 1, b);

\footnotetext{
${ }^{*}$ Corresponding author: andree-va@mail.ru
} 
- a sample of butt joints with transverse weld made by automatic argon arc welding with SvAMg63 filler wire (Fig. 1, c);

- a sample of butt joints with transverse weld made by automatic argon arc welding with SvAMg63 filler wire and technological hole (Fig. 1, d);

- a sample of a butt joint with a longitudinal seam made by automatic argon arc welding with SvAMg63 filler wire (Fig. 1, e);

a sample simulating repair welding of mechanical cuts made by manual argon-arc welding with SvAMg63 filler wire (Fig. 1, f);

To prevent porosity in the weld metal of alloy $01420 \mathrm{C}$, chemical milling with controlled removal of the surface layer by $0.2-0.25 \mathrm{~mm}$ on each side of the sheet was used. Therefore, sheets of alloy 01420 with a thickness of $3.0 \mathrm{~mm}$ were selected before welding. After a controlled removal of a layer with a thickness of $0.20-0.25 \mathrm{~mm}$, the $01420 \mathrm{C}$ alloy blanks were subjected to chemical etching in $\mathrm{NaOH}$ alkali, followed by clarifying in a $30 \%$ nitric acid solution.

Welding of samples of alloy $01420 \mathrm{C}$ was performed on a welding complex for automatic argon arc welding based on the machine VF3M8 with SwAMg63 filler wire of $2.0 \mathrm{~mm}$ in diameter when the arc was supplied from the ISVU-400 power source. The welding modes of the studied alloys are shown in Table 1.

Table 1. Parameters of the automatic argon arc welding mode for samples.

\begin{tabular}{|c|c|c|c|}
\hline $\begin{array}{c}\text { Arc } \\
\text { current, A }\end{array}$ & $\begin{array}{c}\text { Welding } \\
\text { speed, } \mathrm{m} / \mathrm{h}\end{array}$ & $\begin{array}{c}\text { Feed rate of filler } \\
\text { wire, } \mathrm{mm} / \mathrm{min}\end{array}$ & $\begin{array}{c}\text { Flow rate of } \\
\text { shielding gas } \\
\text { (argon) }, \mathrm{dm}^{3} / \mathrm{min}\end{array}$ \\
\hline $95-100$ & 9,6 & 0,69 & $9-12$ \\
\hline
\end{tabular}

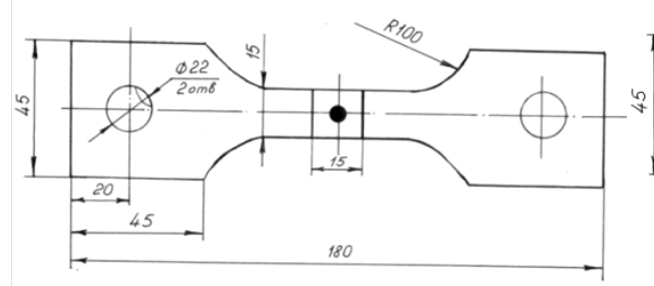

a

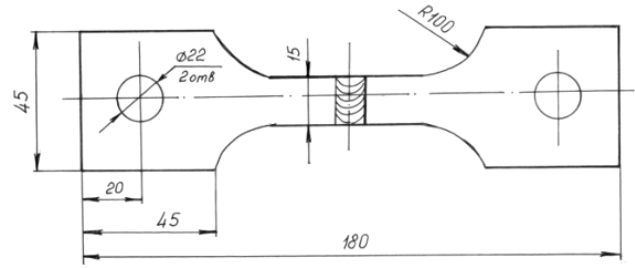

$\mathrm{c}$

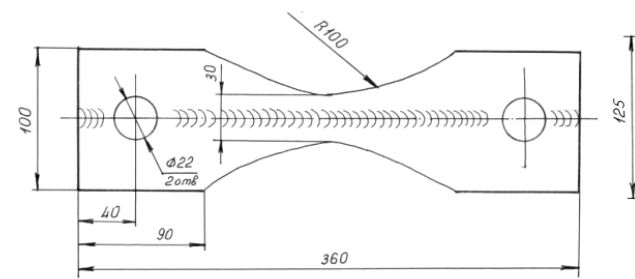

e



b

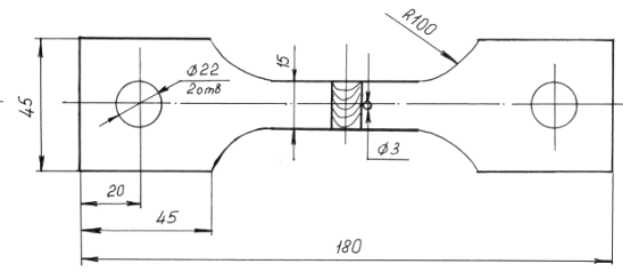

d

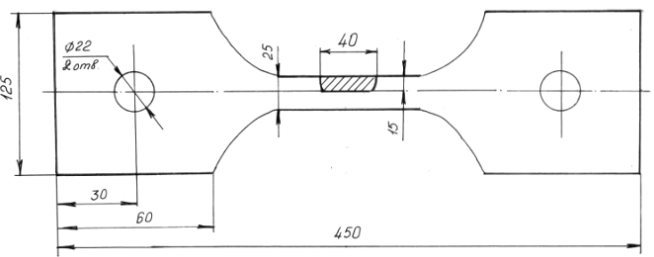

f

Fig. 1. Samples for fatigue testing of welded joints of $01420 \mathrm{~S}$ alloy sheets. 
To prevent the formation of porosity in the fusion zone and in the weld metal, the back of the weld was protected with argon using special technological strips made of stainless steel.

In order to simulate the effect of welding defects in the form of pores, some samples with a transverse weld was produced with a hole of $3 \mathrm{~mm}$ in diameter with a center along the fusion line between the weld metal and the parent metal. Thus, the presence of a defect in the most dangerous zone of the welded joint was simulated.

Resistance spot welding (RSW) of $01420 \mathrm{~S}$ alloy samples was carried out after strengthening treatment, which included quenching $\left(450^{\circ} \mathrm{C}\right.$ with air cooling) and interrupted aging $\left(120^{\circ} \mathrm{C}\right.$ with a 12 -hour soaking). Welding was performed on the welding machine MT75 with the mode shown in Table 2.

Table 2. RSW mode parameters of $01420 \mathrm{~S}$ alloy samples.

\begin{tabular}{|c|c|c|c|}
\hline $\begin{array}{c}\text { Effort of compression } \\
\text { of electrodes during } \\
\text { welding, } \\
\mathrm{N}\end{array}$ & $\begin{array}{c}\text { Duration of the } \\
\text { current pulse, } \mathrm{s}\end{array}$ & $\begin{array}{c}\text { Value of the current } \\
\text { in the pulse, } \mathrm{kA}\end{array}$ & Heating, units \\
\hline 8000 & 0,21 & $5,5-6,2$ & 14 \\
\hline
\end{tabular}

The selection of the mode was carried out based on the results of the analysis of the special samples macrostructure to obtain a joint with the parameters of the welded spot: the diameter of the cast nugget is $7.5-8.2 \mathrm{~mm}$; penetration is not less than $65 \%$ of the sheet thickness.

In the manufacture of samples simulating the repair welding of mechanical cuts, a special groove was milled in the central part of the sample, which was then welded by manual argon arc welding in a special device that prevents from deformation of the sample.

For manual argon arc welding, RGA-150 torch with a tungsten electrode of $2 \mathrm{~mm}$ in diameter, an arc current of 90-95 A, an argon flow rate through the torch nozzle of 10 $\mathrm{dm} 3 / \mathrm{min}$, and a SwAMg63 filler wire of $2.5 \mathrm{~mm}$ in diameter were employed.

After welding, all welded joints were X-rayed for internal defects.

Tests for the durability of welded samples were carried out on a zero cycle with a loading frequency $\mathrm{f}=1-5 \mathrm{~Hz}$. The tests were carried out at several stress levels $\sigma \mathrm{max}-300,150,130$ and $100 \mathrm{MPa}$ on LFV-1000 servo hydraulic machine (Switzerland).

\section{Experimental results and discussion}

Durability tests of welded samples made of 01420 S alloy sheet were carried out on a zero cycle with a loading frequency $\mathrm{f}=1-5 \mathrm{~Hz}$.

The test results of samples with spot welds are presented in Table 3.

Table 3. Durability of $01420 \mathrm{~S}$ alloy spot welds of $2.5 \mathrm{~mm}$ in thickness

\begin{tabular}{|c|c|c|c|c|c|c|c|}
\hline Sample & & f, Hz & $\begin{array}{c}\sigma_{\max } \\
\text { MPa }\end{array}$ & N, cycles & $\begin{array}{c}\text { Average } \\
\text { number of } \\
\text { cycles N, } \\
\text { cycles }\end{array}$ & Lg N & S \\
\hline Fig 1, a & & 5 & 300 & $4239-17240$ & 9926 & 4,00 & 0,26 \\
\cline { 2 - 8 } & & 5 & 150 & $38520-314160$ & 100707 & 5,00 & 0,26 \\
\hline \multirow{2}{*}{ Fig 1, b } & & 5 & 200 & $2730-6010$ & 4264 & 3,63 & 0,14 \\
\cline { 2 - 8 } & & 5 & 75 & $118700-471500$ & 258484 & 5,41 & 0,25 \\
\hline
\end{tabular}

To evaluate the structural and technological quality of a structural element, the fatigue strength coefficient, which reflects the difference in durability between the structural element and the strip with a hole is used: 


$$
K_{y}=\frac{3 \cdot \sigma_{p o}}{\sigma_{e l}},
$$

where $\sigma_{\mathrm{po}}$ and $\sigma_{\mathrm{el}}$ are the fatigue strength of the strip with the hole and the element on this base, respectively.

For samples with an unloaded weld spot (Fig. 1, b) in the loading range from 104 to 105 cycles, Ky $=2.55$ (on average).

The general view of the destroyed samples is shown in Fig. 2.

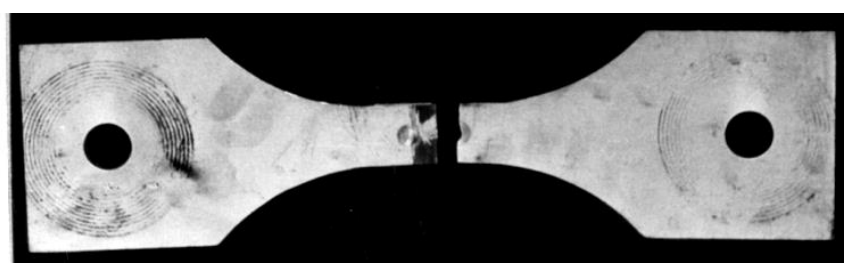

Fig. 2. Destruction of samples with an unloaded weld spot.

Samples with a strip welded by spot welding, simulating the edge line of a reinforced structural element were tested at two stress levels: $\sigma_{1 \max }=200 \mathrm{MPa}$ and $\sigma_{2 \max }=75 \mathrm{MPa}$. Tests have shown that the durability of such a joint is almost 5 times lower than the durability of a strip with a hole. Figure 3 shows the sample after the tests.

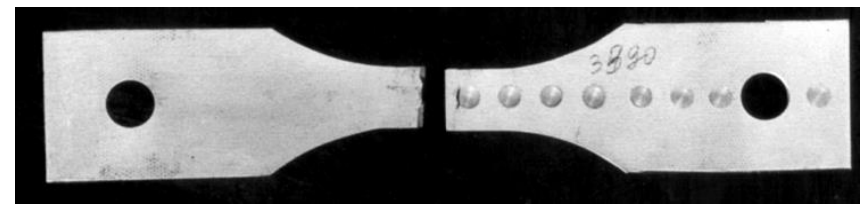

Fig. 3. Destruction of samples simulating the edge line of the reinforcing element.

The test results of welded joints samples performed by automatic argon arc welding are presented in Table 4.

For samples with a transverse seam made of $01420 \mathrm{~S}$ alloy, the durability of the joints at a cycle voltage of $150 \mathrm{MPa}$ is 16757 cycles. For samples with a longitudinal weld, an increase in durability is observed up to 352387 cycles.

It should be noted that there is a large value of dispersion $(\mathrm{S}=0.53)$ in durability range for all stress levels in samples of this type.

Table 4. Durability of $01420 \mathrm{~S}$ alloy spot welds of $2.5 \mathrm{~mm}$ in thickness, made by argon arc welding.

\begin{tabular}{|c|c|c|c|c|c|c|}
\hline Sample & $\mathrm{f}, \mathrm{Hz}$ & $\begin{array}{c}\sigma \mathrm{max} \\
\mathrm{MPa}\end{array}$ & $\mathrm{N}$, cycles & $\begin{array}{l}\text { Average } \\
\text { number of } \\
\text { cycles } \mathrm{N}, \\
\text { cycles }\end{array}$ & $\lg \dot{N}$ & $\mathrm{~S}$ \\
\hline \multirow[t]{2}{*}{ Fig. 1, c } & 5 & 150 & $2800-54502$ & 16757 & 4,22 & 0,51 \\
\hline & 5 & 100 & $71640-318620$ & 136931 & 5,14 & 0,25 \\
\hline \multirow[t]{2}{*}{ Fig. 1, d } & 5 & 150 & $8840-24790$ & 18391 & 4,26 & 0,21 \\
\hline & 5 & 100 & $51680-245720$ & 111478 & 5,05 & 0,30 \\
\hline \multirow[t]{2}{*}{ Fig. 1, e } & 5 & 300 & $22100-27810$ & 24786 & 4,39 & 0,44 \\
\hline & 5 & 150 & $165780-622700$ & 352287 & 5,55 & 0,22 \\
\hline \multirow[t]{2}{*}{ Fig. 1, f } & 5 & 200 & $5750-53640$ & 25843 & 4,41 & 0,35 \\
\hline & 5 & 100 & $143090-805820$ & 375080 & 5,57 & 0,25 \\
\hline
\end{tabular}

In order to simulate the effect of welding defects, mainly in the form of pores, some samples with a transverse seam were made with a hole of $3 \mathrm{~mm}$ in diameter with a center 
along the fusion line between the weld and the parent metal. Thus, destruction was assumed to occur in the most dangerous zone of the welded joint $[3,4]$.

The tests showed that there were samples whose destruction occurred along the fusion line from the side of the weld, and where there was no hole. This means that simulation of a pore by a hole can result in misconceptions of the fatigue resistance characteristics of the real joint. This is confirmed by comparing the durability dispersion of joints with a hole $(\mathrm{S}=$ 0.09-0.32) and without it ( $\mathrm{S}=0.25-0.53)$ (Table 4).

The nature of the destruction of samples with a transverse seam and a hole made of 01420S alloy is shown in Fig. 4. As a result of metallographic analysis, it was found that on the studied samples of welded joints with a transverse weld and a hole in the fusion zone the destruction occurred from the hole.

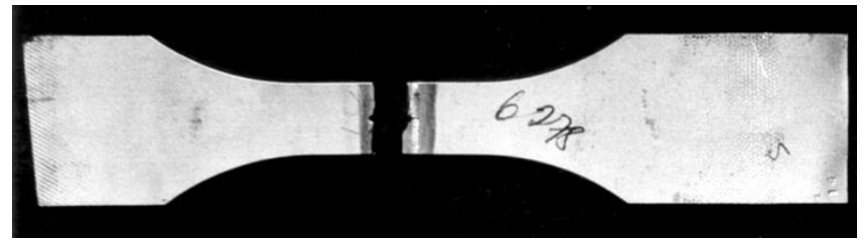

a



b

Fig. 4. Destruction of samples with a transverse seam and a hole on the fusion line (a) and only a transverse seam (b).

Samples with a longitudinal weld outclass in terms of durability the samples with a transverse seam. The destruction of such samples during the tests occurred from the edge of the sample (Fig. 5).



Fig. 5. Destruction of samples with a longitudinal weld.

Samples simulating repair welding of mechanical cuts are almost similar in durability to samples in the form of a strip with a hole.

After testing the samples, the fractures were subjected to metallographic analysis. As a result of this analysis, it was found that the structure the fractures for different types of samples differs significantly. So it was shown that on structural samples with technological holes, the destruction occurred near the hole.

The nature of the destruction of samples with surfacing shows a pronounced fatigue zone, which occupies more than $50 \%$ of the sample cross-section. The fatigue zone is divided into two areas: a bright shiny area is the area of the deposited metal and a dull one is typical to 
the parent metal. As a rule, the destruction occurs in the surfacing zone caused by welding defects, or from the angle of the sample also in this zone (Fig. 6, a). Decomposition is present in the parent metal of the deposited samples (Fig. 6, b).

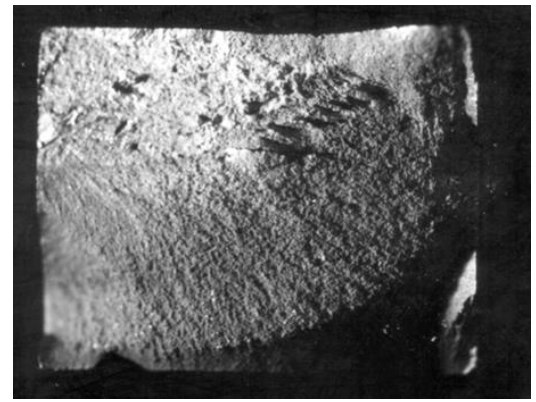

a

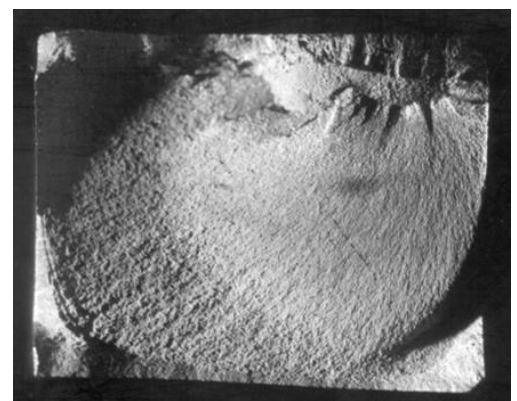

$\mathrm{b}$

Fig. 6. Fractures of samples with back run of the mechanical cut: a - 20090 cycles; b-245320 cycles

On sheet samples with a transverse seam with a hole, the destruction occurs from the hole. On sheet samples without a hole, two types of fracture are observed: along the fusion line from the concentrator formed by the convexity of the weld, and along the center of the weld. In samples damaged in the center of the weld, as a rule, there is lack of fusion along the edge in the middle of the cross-section. Thus, in samples that damaged during the first half-cycle, lack of fusion is about $60 \%$ of the cross-section.

The analysis of the sample destruction with a small number of cycles usually occurs on the fusion line. At the same time, a brittle fracture of ripple shape is observed, repeating the fusion line. This type of failure appears to be a specific feature of the $01420 \mathrm{~S}$ alloy (Fig. 7).

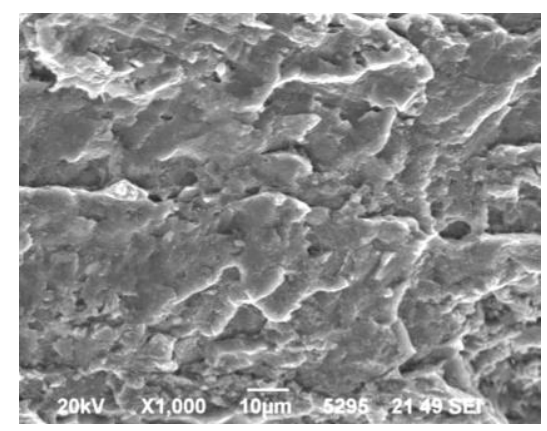

Fig. 7. Fractograph of the surface fracture of the $01420 \mathrm{~S}$ alloy welded joint sample with the number of cycles to failure 5750 .

During the fatigue tests of several samples produced by spot welding in order to study the kinetics of the nucleation and propagation of fatigue cracks, an ultrasonic testing was performed. The testing was carried out by an inclined combined transducer with a prism angle of $40^{\circ}$ at a frequency of $2.5 \mathrm{MHz}$. Ultrasonic vibrations were applied on the sample side opposite to the crack nucleation place. In samples made by spot welding, the crack usually originates in the heat-affected zone of the weld spot above the lap.

Passing through the weld spot ultrasonic vibrations are transformed into normal waves in the lower sheet. Reflecting from the incipient crack, normal waves generate a signal in the form of a separate pulse, which is observed on the screen of the flaw detector. The amplitude of this pulse carries information about the defect flaw. The test is performed approximately every 500 operating cycles at a frequency of $5 \mathrm{~Hz}$. The results of the ultrasound test are shown in Table 5. 
The analysis of the results obtained showed that the moment of crack nucleation is approximately half of the total durability of the sample.

Table 5. Kinetics of fatigue crack propagation

\begin{tabular}{|c|c|c|c|c|}
\hline Sample & $\sigma_{\max }, \mathrm{MPa}$ & N0, cycles & $\begin{array}{c}\text { The number of } \\
\text { cycles of crack } \\
\text { exit to the surface }\end{array}$ & $\begin{array}{c}\text { The number of } \\
\text { cycles before } \\
\text { fracture }\end{array}$ \\
\hline Fig.1,b & 200 & $1400-2000$ & $2100-3000$ & $2730-3390$ \\
\cline { 2 - 5 } & 100 & 15800 & 28600 & 31200 \\
\hline Fig.1, a & 300 & 7300 & 12540 & 14850 \\
\hline
\end{tabular}

\section{Conclusions}

1. Experimental values of the fatigue characteristic of $01420 \mathrm{~S}$ alloy welded sheets with a different location of the weld are obtained.

2. For welded joints of $01420 \mathrm{C}$ alloy sheets, the value of the fatigue durability of joints with a longitudinal weld exceeds its values of the samples with a transverse seam at the same level of cycle stresses.

3. Joints made by resistance spot welding and simulating the edge line of a reinforced element, have durability approximately by an order less than the durability of the joint produced by RSW with an unloaded weld spot. At the same time, the latter have durability about half that of the sample with a longitudinal weld.

4. The durability of elements of limited cross-section with repair welding of a mechanical cut is almost equal to the durability of the standard sample in the form of a strip with a hole.

5. For welded joints of $01420 \mathrm{~S}$ alloy sheets, there is an increased dispersion of the fatigue durability characteristics (up to $\mathrm{S}=0.53$ ), especially for samples with a transverse seam.

6. As a result of metallographic analysis, it was found that on the studied samples of welded joints with a transverse seam and a hole in the fusion zone, the destruction occurs from the hole. In this case, the value of fatigue durability is reduced in comparison with the sample without a concentrator in the form of a hole.

\section{References}

1. Matsnev V. N. Research of technological possibilities of Al-Li-alloy 01421 for diewelded integral structures / V. N. Matsnev, V. I. Ryazantsev, S. F. Danilov / / Aviation industry. (3) - pp. 36-42. (2004)

2. Labur T. M. Interrelation of resistance to destruction and structural transformations during welding of alloy 1422. / T. M. Labur, A. Ya. Ishchenko, T. G. Taranova, G. M. Grigorenko, V. A. Kostin, A. A. Chaika/ / Welding production. (5) - pp. 3-8. (2013)

3. Grushko O. E. Aluminum-lithium alloys: metallurgy, welding, metal science: Monograph. / O. E. Grushko, B. V. Ovsyannikov, V. V. Ovchinnikov (Moscow: Nauka, 2014. - 298 p.)

4. Rudzey G. F. Influence of welding defects and the number of repair passes on the fatigue resistance of welded joints made of aluminum alloys. // Welding production. (11) - pp. 32-35. (2013) 